\title{
Effect of Pre-treatment Methods on the Color Changes during Drying of Red Chilli (Capsicum frutescens L.)
}

\author{
Rattapon Saengrayap ${ }^{1, a}$, Natthida Boonlap ${ }^{1}$, and Uthumporn Boonsorn ${ }^{1}$ \\ ${ }^{1}$ Department of Agro-Industry Technology and Management, Faculty of Agro-Industry, King Mongkut's University of Technology North \\ Bangkok (KMUTNB) Prachinburi Campus, Prachinburi, Thailand
}

\begin{abstract}
Chilli was dried using conventional tray dryer with 3 different drying conditions, i.e., $60^{\circ} \mathrm{C}, 80^{\circ} \mathrm{C}$ and 2stage drying $\left(80^{\circ} \mathrm{C}\right.$ and $\left.60^{\circ} \mathrm{C}\right)$. The effects of pre-treatment methods were evaluated by soaking chilli in pre-treatment solutions prior to drying. In terms of drying characteristics, the drying time found to be shortest at $80^{\circ} \mathrm{C}$. It was also found that the drying rate of pre-treated chilli increased compared with non-treated one. The modified Page's model was suitable for describing drying characteristics at all conditions $\left(\mathrm{R}^{2}=0.97-0.99\right)$. Furthermore, the color change during drying was investigated using image analysis methods. It was found that the pre-treatment methods prevented the color change. The combined kinetic model was the best model for predicting the change of color during drying $\left(R^{2}=0.98-0.99\right)$. A pre-treated chilli soaking in a mixed solution of $0.3 \%(\mathrm{w} / \mathrm{w}) \mathrm{Na}_{2} \mathrm{~S}_{2} \mathrm{O}_{5}$ and $1 \%(\mathrm{w} / \mathrm{w}) \mathrm{CaCl}_{2}$ showed the better quality. In addition, the combined kinetics model could describe the change of $L^{*} a^{*}$ and $b^{*}$ values in all conditions.
\end{abstract}

\section{Introduction}

Chilli is one of spice products that used as the condiments for flavoring and coloring in cuisines. Chilli is a good source of flavonoids, i.e., carotenoids and vitamin $\mathrm{C}$, which their antioxidant activities confer the protection against carcinogenic compounds and delay the aging process $[1,2]$.

Generally, the conventional drying method for chilli is sun drying, and remains the most practical method throughout chilli producing countries including Thailand, that takes several days to obtain the required moisture content $(4-11 \%$ d.b.) $[3,4]$. However, sun drying method causes a major loss of qualities of the final product, due to the long drying time and direct exposure to the surroundings. Undesirable changes in the color attributes of the chilli may lead to a decrease in its quality and marketing value [5-7]. Moreover, hot air drying is another common method for drying chilli.

Browning reaction is the important phenomenon that tends to decrease the quality of dried products [8-10]. Many methods were applied to improve the quality of dried products. The pre-treatment step was achieved to prevent the change in qualities of many processed food. Blanching with hot water and soaking in chemical solutions were extensively used for solving the change of dried product [11-14].

Color is considered to be a major criterion which affects the consumer's perception. Normally, the colorimeter is successfully achieved to measurement the color but the limitation of colorimeter can be found when

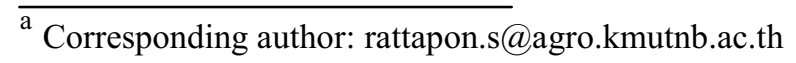

determine the non-homogeneous color of solid samples. Moreover, low repeatability unrepresentative results are found when use colorimeter on small surface area. Therefore, an alternative method is proposed which is the use of digital image analysis. The digital image analysis has been successfully applied in many food industrial applications such as classification, grading and estimating qualities [15-18].

Therefore, the objectives of this study were to study the effect of pretreatment methods on the change in drying characteristics and to determine the change in color during drying using image analysis method.

\section{Materials and Methods}

\subsection{Materials}

Fresh red chilli (Capsicum frutescens L.) was procured from a local market then washed and graded prior to storage in a refrigerator at $5^{\circ} \mathrm{C}$. Initial moisture content of chilli was determined using AOAC method 920.151A [19]. The initial moisture content of chilli was $85.53 \pm 0.04 \%$ wet basis.

\subsection{Pre-treatment methods}

Chilli was blanched using hot water at $90^{\circ} \mathrm{C}$ for $3 \min [10]$ and then cooled in cold water at $5^{\circ} \mathrm{C}$ for $5 \mathrm{~min}$ and drained on a perforated tray prior to soak in pretreatment solutions. Blanched chilli was soaked in the controlled 
temperature pre-treatment solutions of $25 \pm 1^{\circ} \mathrm{C}$ for $10 \mathrm{~min}$ The operating ratio was $1: 2(\mathrm{w} / \mathrm{w})$ for chilli and solution, respectively. The mixed pre-treated solutions were consists of (1) $0.1 \%(\mathrm{w} / \mathrm{w}) \mathrm{Na}_{2} \mathrm{~S}_{2} \mathrm{O}_{5}$ and $1 \%(\mathrm{w} / \mathrm{w}) \mathrm{CaCl}_{2}$; (2) $0.2 \%(\mathrm{w} / \mathrm{w}) \mathrm{Na}_{2} \mathrm{~S}_{2} \mathrm{O}_{5}$ and $1 \%(\mathrm{w} / \mathrm{w}) \mathrm{CaCl}_{2}$; (3) $0.3 \%$ (w/w) $\mathrm{Na}_{2} \mathrm{~S}_{2} \mathrm{O}_{5}$ and $1 \%(\mathrm{w} / \mathrm{w}) \mathrm{CaCl}_{2}$; and (4) blanched chilli without soaking were used as a control group. However, in this study, according to the food safety and to avoid an allergic reaction in those who are sensitive to the residues of $\mathrm{Na}_{2} \mathrm{~S}_{2} \mathrm{O}_{5}$ and $\mathrm{CaCl}_{2}$; the concentration of $\mathrm{Na}_{2} \mathrm{~S}_{2} \mathrm{O}_{5}$ and $\mathrm{CaCl}_{2}$ was then controlled to be lower than the limitation of food additive usage of $\mathrm{Na}_{2} \mathrm{~S}_{2} \mathrm{O}_{5}$ and $\mathrm{CaCl}_{2}$ by Thailand FDA.

\subsection{Drying procedures}

A laboratory hot-air dryer (Memmert, UF750, Germany) was used to dry chilli. The temperature was control at $60^{\circ} \mathrm{C}$ and $80^{\circ} \mathrm{C}$ with air velocity $2.0 \mathrm{~m} / \mathrm{s}$. Another 2 -stage drying was performed using initial temperature of $80^{\circ} \mathrm{C}$ for $5 \mathrm{hr}$ following by $60^{\circ} \mathrm{C}$ for a final stage. Temperature was monitored using a type-T thermocouple which connected with a data logger (Fluke, 714B, USA). The drying process continues until the sample mass was constant. After drying process finished, the sample was placed in a desiccator for cooling down temperature prior to pack in an aluminum bag, and then kept in a desiccator for further quality evaluations.

\subsection{Drying characteristics}

The effects of drying methods and drying conditions on drying characteristics were determined. The average moisture ratio $(M R)$ was calculated using Eq. (1):

$$
M R=M-M_{e} / M_{0}-M_{e}
$$

Where $M$ is sample moisture content (d.b.), $M_{0}$ is initial moisture content (d.b.), and $M_{e}$ is the equilibrium moisture content.

\subsection{Color measurement}

Surface colors of chilli were measured using a colorimeter (HunterLab, ColorQuest XE Plus, Reston, VA, USA). Color was expressed in CIELAB, i.e., $L^{*}$ (whiteness or brightness), $a^{*}$ (redness/greenness) and $b^{*}$ (yellowness/blueness) coordinates, standard illuminant D65 and observer $10^{\circ}$. The calorimeter was calibrated against a standard white plate $\left(L^{*}=91.7, a^{*}=-1.16\right.$, $\left.b^{*}=1.06\right)$ before color measurement. The sample was measured three times with three different positions and then reported the data as an average value of the measurements. Total color changes $(\Delta E)$, Chroma $(C)$, hue angle $\left({ }^{\circ} h\right)$ and browning index $(B I)$ were calculated using following by Eqs. (2-5):

$$
\begin{gathered}
\Delta E=\sqrt{\left(L^{*}-L_{0}^{*}\right)^{2}+\left(a^{*}-a_{0}^{*}\right)^{2}+\left(b^{*}-b_{0}^{*}\right)^{2}} \\
C=\sqrt{a^{* 2}+b^{* 2}}
\end{gathered}
$$

$$
\begin{gathered}
h^{\circ}=\tan ^{-1}\left(b^{*} / a^{*}\right) \\
B I=[100(x-0.31)] / 0.71
\end{gathered}
$$

Where $L_{0}^{*}, a_{0}^{*}$ and $b_{0}^{*}$ are initial color parameters of the chilli; $x=\left(a^{*}+1.75 L^{*}\right) /\left(5.645 L^{*}+a^{*}-0.3012 b^{*}\right)$

\subsection{Image analysis}

\subsubsection{Image acquisition system}

The image acquisition system (Figure 1.) consists of an illumination system, a digital camera and a computer to acquire the RGB images. A light box (Medalight Model DIB-0806, Hong Kong) was used as a light source. A digital camera (NIKON, D60, Japan) was mounted with the built-in camera holder on the top of the light box and connected with a computer (Fujitsu, Lightbook B531, Japan) via a USB port for directly capturing the images by a remote control utility software (NIKON, Camera Control Pro 2 - Trial version, Japan).

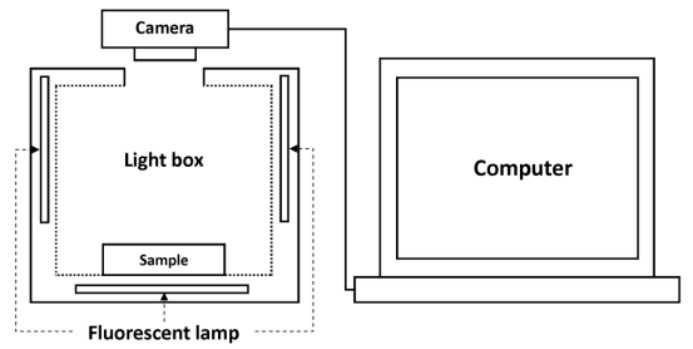

Figure1. Image acquisition system

\subsubsection{Calibration and color conversion}

Calibration of the image acquisition system was conducted to compare the results between the image analysis method with those of conventional one. The standard color sheets were measured using both a colorimeter (HunterLab, ColorQuest XE Plus, Reston, VA, USA) and image analysis method. The images from image acquisition system were then analyzed using image processing algorithm which developed in MATLAB (V2008a, MathWork, Inc., MA, USA). The accuracy for the use of machine vision could be determined using the following equations:

$$
\Delta E=\sqrt{\left(L_{c}^{*}-L^{*}\right)^{2}+\left(a_{c}^{*}-a^{*}\right)^{2}+\left(b_{c}^{*}-b^{*}\right)^{2}}
$$

Where $L^{*}, a^{*}$ and $b^{*}$ were the actual lightness, redness and yellowness values from colorimeter, respectively; $L_{\mathrm{c}}{ }^{*}, a_{\mathrm{c}}{ }^{*}$ and $b_{\mathrm{c}}{ }^{*}$ were the converted lightness, redness and yellowness values, respectively.

\subsection{Kinetics model}

\subsubsection{Drying kinetics}

The obtained drying curves undergoing different methods were fitted with five different models given in Table 1. The models were tested for their validity in describing 
drying characteristics of chilli. The coefficients in each model were determined using STATISTICA $^{\star}$ (Version 6.0, StatSoft, Tulsa, Okla., U.S.A.). The suitable model was selected using the standard error $(S E)$ and the coefficient of detrmination $\left(R^{2}\right)$. The best fit model would provide a lowest $S E$ with highest $R^{2}$ [20].

Table 1. Mathematical models applied to the drying curves

\begin{tabular}{|c|l|}
\hline Model & Model equation \\
\hline Newton & $M R=\exp (-k t)$ \\
\hline Modified Page & $M R=\exp \left[-(k t)^{n}\right]$ \\
\hline Henderson and Pabis & $M R=a \exp (-k t)$ \\
\hline Logarithmic & $M R=a \exp (-k t)+c$ \\
\hline Wang and Singh & $M R=1+a t+b t^{2}$ \\
\hline
\end{tabular}

Note: $k$, Drying coefficient in $\min ^{-1} ; n$, exponent (dimensionless); $t$, time in $\min ; a, b$ and $c$, coefficient (dimensionless), specific to individual equations.

\subsubsection{Color kinetics}

In order to determine the change of color during drying, chilli was taken from the dryer 30 min interval for each drying condition. Chilli was taken an image using the developed image acquisition system. The RGB values were then determined and converted to CIELAB using MATLAB. The converted CIELAB values in terms of the normalized color differences were plotted as a function of drying time. Several equations were reported to describe the color kinetics [21-23]. Generally, the rate of change of color can be expressed by the following equation:

$$
\frac{d C}{d t}= \pm k C^{n}
$$

Where $k$ is the kinetic rate constant; $C$ is the concentration of quality factor at time $\mathrm{t}$ and $n$ is the order of reaction.

The time dependent relationships for most foods appear to be described by zero-order or first order kinetic model. By integrating Eq. (7), the zero order equation, the first order equation and the combined kinetic models equation could be derived as [24]:

The zero order equation: $C=C_{0} \pm k_{0} t$

The first order equation: $C=C_{0} \exp \left( \pm k_{1} t\right)$

The combined kinetic models equation:

$$
C=\frac{k_{0}}{k_{1}}-\left[\left(\frac{k_{0}}{k_{1}}-C_{0}\right) \exp \left( \pm k_{1} t\right)\right]
$$

Where $C_{0}$ is the initial value of color and $C$ is the color value at a specified time. Moreover, in the equation, a positive $(+)$ and a negative $(-)$ values indicated the formation and degradation of any quality parameter, respectively [24].

\section{Results and Discussion}

\subsection{Drying characteristics of chilli}

The results showed that the temperature affected the drying characteristics of chilli. Drying at a higher temperature of $80^{\circ} \mathrm{C}$ presented lower drying time for all drying conditions. Drying time of chilli is shown in Table 2. It was observed that the pre-treated chilli showed the lower rate of moisture removal than those of non-treated one. This might due to the fact that the blanching and soaking processes increased the moisture content of chilli. A significant amount of moisture was absorbed into chilli and then resulted in a higher time for drying chilli to reach the desired moisture content $(9-11 \%$ w.b.). In addition, the concentration levels of the mixed pretreatment solutions on the drying time had no significant difference in each drying temperature.

Table 2. Drying time of chilli undergoing different pretreatment conditions

\begin{tabular}{|c|c|c|c|}
\hline \multirow{2}{*}{ Pre-treatment } & \multicolumn{3}{|c|}{ Drying time (h) } \\
\cline { 2 - 4 } & $\mathbf{6 0}^{\circ} \mathbf{C}$ & $\mathbf{8 0}^{\circ} \mathbf{C}$ & 2-stage \\
\hline Non-treated & 12 & 4.5 & 8 \\
\hline Blanching & 14 & 5.5 & 9.5 \\
\hline $0.1 \% \mathrm{Na}_{2} \mathrm{~S}_{2} \mathrm{O}_{5}$ and $1 \% \mathrm{CaCl}_{2}$ & 13.5 & 5 & 8.5 \\
\hline $0.2 \% \mathrm{Na}_{2} \mathrm{~S}_{2} \mathrm{O}_{5}$ and $1 \% \mathrm{CaCl}_{2}$ & 13.5 & 6 & 8.5 \\
\hline $0.3 \% \mathrm{Na}_{2} \mathrm{~S}_{2} \mathrm{O}_{5}$ and $1 \% \mathrm{CaCl}_{2}$ & 13 & 6 & 8 \\
\hline
\end{tabular}

Table 3. The prediction errors of modified Page models for describing the drying characteristics of chilli undergoing $80^{\circ} \mathrm{C}$

\begin{tabular}{|c|c|c|}
\hline Pre-treatment & $\boldsymbol{S} \boldsymbol{E}$ & $\boldsymbol{R}^{\mathbf{2}}$ \\
\hline Non-treated & 0.02 & 0.98 \\
\hline Blanching & 0.01 & 0.99 \\
\hline $0.1 \% \mathrm{Na}_{2} \mathrm{~S}_{2} \mathrm{O}_{5}$ and $1 \% \mathrm{CaCl}_{2}$ & 0.01 & 0.98 \\
\hline $0.2 \% \mathrm{Na}_{2} \mathrm{~S}_{2} \mathrm{O}_{5}$ and $1 \% \mathrm{CaCl}_{2}$ & 0.01 & 0.97 \\
\hline $0.3 \% \mathrm{Na}_{2} \mathrm{~S}_{2} \mathrm{O}_{5}$ and $1 \% \mathrm{CaCl}_{2}$ & 0.01 & 0.98 \\
\hline
\end{tabular}

Among the pre-treatment methods, chilli soaking in $0.3 \%(\mathrm{w} / \mathrm{w}) \mathrm{Na}_{2} \mathrm{~S}_{2} \mathrm{O}_{5}$ and $1 \%(\mathrm{w} / \mathrm{w}) \mathrm{CaCl}_{2}$ showed lower drying time at $60^{\circ} \mathrm{C}$ and 2-stage drying for $13 \mathrm{~h}$ and $8 \mathrm{~h}$, respectively. On the other hand, according to the drying time, chilli soaking in $0.1 \%(\mathrm{w} / \mathrm{w}) \mathrm{Na}_{2} \mathrm{~S}_{2} \mathrm{O}_{5}$ and $1 \%(\mathrm{w} / \mathrm{w})$ $\mathrm{CaCl}_{2}$ showed the lowest drying time at $80^{\circ} \mathrm{C}$ for $5 \mathrm{~h}$. The chemical components in the pre-treatment solutions, especially, $\mathrm{Na}$ and $\mathrm{Ca}$ salts were reported to alter the cellular structure of chilli resulting in increased the moisture removal $[3,11]$.

Table 4. The coefficient of modified Page models for describing the drying characteristics of chilli undergoing $80^{\circ} \mathrm{C}$

\begin{tabular}{|c|c|c|}
\hline Pre-treatment & $\boldsymbol{k}$ & $\boldsymbol{n}$ \\
\hline Non-treated & 0.13 & 1.19 \\
\hline Blanching & 0.10 & 1.24 \\
\hline $0.1 \% \mathrm{Na}_{2} \mathrm{~S}_{2} \mathrm{O}_{5}$ and $1 \% \mathrm{CaCl}_{2}$ & 0.22 & 1.27 \\
\hline $0.2 \% \mathrm{Na}_{2} \mathrm{~S}_{2} \mathrm{O}_{5}$ and $1 \% \mathrm{CaCl}_{2}$ & 0.18 & 1.19 \\
\hline $0.3 \% \mathrm{Na}_{2} \mathrm{~S}_{2} \mathrm{O}_{5}$ and $1 \% \mathrm{CaCl}_{2}$ & 0.19 & 1.21 \\
\hline
\end{tabular}

Table 3 shows the results for selecting the suitable model for describing the drying behaviour of chilli undergoing different pre-treatment conditions. It was 
observed that the modified Page model was the best model for predicting the change of moisture removal comparing with other models. It provided the lowest $S E$ and highest $R^{2}$ in all condition of drying. Therefore, modified Page model was then selected for predicting drying characteristics of chilli. Table 4 shows the parameter and drying coefficient of the selected model.

\subsection{Effect of pre-treatment on color change}

Figure 2 shows the change of color parameters of chilli undergoing different pre-treatment methods at $60^{\circ} \mathrm{C}$. The $\Delta E$ was found to be lower when chilli was soaked in pretreatment solutions. The lowest change of $\Delta E$ was at $0.3 \%(\mathrm{w} / \mathrm{w}) \mathrm{Na}_{2} \mathrm{~S}_{2} \mathrm{O}_{5}$ and $1 \%(\mathrm{w} / \mathrm{w}) \mathrm{CaCl}_{2}$ with had no significant different between levels of concentration. On the other hand, the fresh chilli and only fresh blanched chilli had higher $\Delta E$ values.

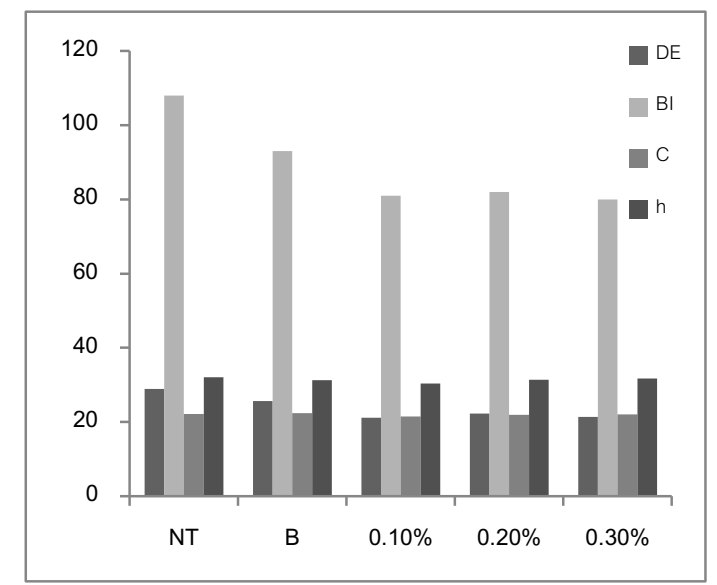

Figure 2. Color attributes of chilli undergoing different pretreatment methods at $60^{\circ} \mathrm{C}(\mathrm{DE}, \Delta \mathrm{E} ; \mathrm{BI}$, Browning index; $\mathrm{C}$, Chroma; h, hue angle; NT, Non-treated; B, Blanching; $0.10 \%$, $0.1 \% \mathrm{Na}_{2} \mathrm{~S}_{2} \mathrm{O}_{5}$ and $1 \% \mathrm{CaCl}_{2} ; 0.2 \%, 0.3 \% \mathrm{Na}_{2} \mathrm{~S}_{2} \mathrm{O}_{5}$ and $1 \%$ $\mathrm{CaCl}_{2} ; 0.3 \%, 0.3 \% \mathrm{Na}_{2} \mathrm{~S}_{2} \mathrm{O}_{5}$ and $1 \% \mathrm{CaCl}_{2}$ )

Drying at higher temperature $\left(80^{\circ} \mathrm{C}\right)$ resulted in higher change of $\Delta E$ as expected. The surface of chilli became darker due to a larger extension of non-enzymatic browning reaction, especially at higher drying temperature [25-29]. According to the 2-stage drying, higher temperature was applied at the initial stage of drying (the first $4 \mathrm{~h}$.) and a lower temperature was then applied. It was observed that a color was found to be better compared to a 1-stage drying at $80^{\circ} \mathrm{C}$ while the $\Delta E$ values were still found to be larger than those of 1-stage drying at $60^{\circ} \mathrm{C}$. This might be due to the fact that the thermal degradation of some color pigments and nonenzymatic browning reaction were occurred during the initial stage of drying.

Furthermore, in terms of $B I$, the results revealed that non-treated sample presented a significant higher $B I$ values compared to the pre-treated one. It was also found that $0.3 \%(\mathrm{w} / \mathrm{w}) \mathrm{Na}_{2} \mathrm{~S}_{2} \mathrm{O}_{5}$ and $1 \%$ (w/w) $\mathrm{CaCl}_{2}$ provided lowest $\mathrm{BI}$ value while the level of concentration did not have significant effect on the $B I$. The presence of browning reaction during drying resulted in the higher $B I$ values of chilli drying at $80^{\circ} \mathrm{C}$ and 2-stage drying when compared to drying at $60^{\circ} \mathrm{C}$ as well. Moreover, all chroma values were in the same range (20.58-22.49) with no significant different. Higher value refers to the purity of red color relating with the present of carotenoids within the chilli $[3,11]$. In terms of $h^{\circ}$ values, it showed similar results with chroma values. There were no significant different between all drying condition. The values of $h^{\circ}$ were in the range of 30.99-33.36 which exhibited a reddish-orange color.

\subsection{Image analysis}

The results showed the compromise in the using of image analysis. The conversion of CIELAB values from RGB values showed a high accuracy and had no significantly different between the converted CIELAB values and those of conventional method.

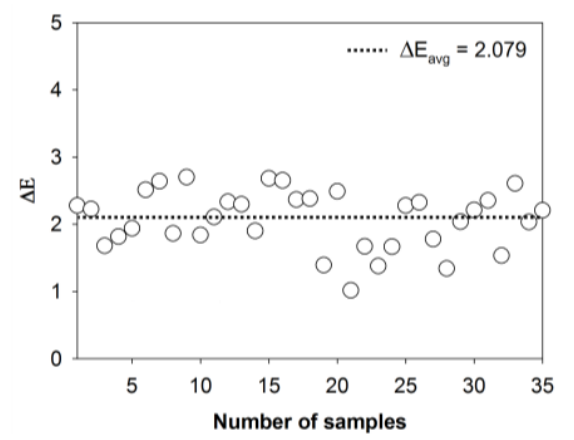

Figure 3. The total color difference and the average total color difference between converted and actual values of the dried chilli

The average $\Delta E$ was 2.079 (Figure 3) with standard deviation of 0.48 . The average $\Delta E$ was below the threshold value of 2.2; which shows the effectiveness of developed image analysis process and machine vision system.

\subsection{Color change kinetics}

In terms of lightness changes chilli became darker than the fresh one. Figure 4 shows the kinetics of the lightness change as a function of drying time at $80^{\circ} \mathrm{C}$. The lightness values decreased during drying due to the browning reactions during drying. The rate of lightness change was also greater at higher temperature.

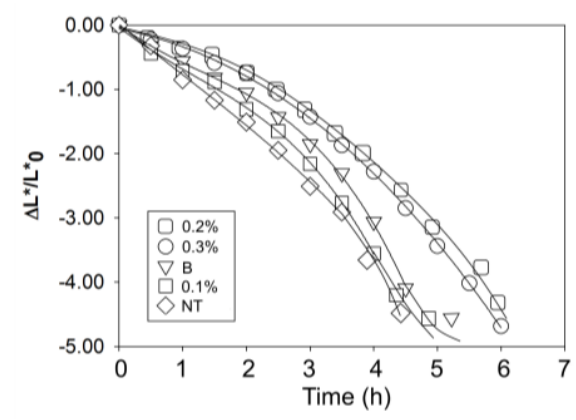

Figure 4. Kinetics of the lightness change as a function of drying time undergoing different pre-treatment methods at $80^{\circ} \mathrm{C}$ (DE, $\triangle \mathrm{E}$; BI, Browning index; $\mathrm{C}$, Chroma; $\mathrm{h}$, hue angle; NT, Non-treated; B, Blanching; $0.10 \%, 0.1 \% \mathrm{Na}_{2} \mathrm{~S}_{2} \mathrm{O}_{5}$ and $1 \%$ $\mathrm{CaCl}_{2} ; 0.2 \%, 0.3 \% \mathrm{Na}_{2} \mathrm{~S}_{2} \mathrm{O}_{5}$ and $1 \% \mathrm{CaCl}_{2} ; 0.3 \%, 0.3 \%$ $\mathrm{Na}_{2} \mathrm{~S}_{2} \mathrm{O}_{5}$ and $1 \% \mathrm{CaCl}_{2}$ ) 
Table 5-6 show the estimated parameters and prediction error values of the combined kinetics models for lightness values of chilli undergoing $80^{\circ} \mathrm{C}$.

Table 5. The estimated parameter of the combined kinetics models for lightness values of chilli undergoing $80^{\circ} \mathrm{C}$

\begin{tabular}{|c|c|c|}
\hline Pre-treatment & $\boldsymbol{k}_{\mathbf{0}}$ & $\boldsymbol{k}_{\mathbf{1}}$ \\
\hline Non-treated & -0.082 & -0.078 \\
\hline Blanching & -0.061 & -0.076 \\
\hline $0.1 \% \mathrm{Na}_{2} \mathrm{~S}_{2} \mathrm{O}_{5}$ and $1 \% \mathrm{CaCl}_{2}$ & -0.137 & -0.067 \\
\hline $0.2 \% \mathrm{Na}_{2} \mathrm{~S}_{2} \mathrm{O}_{5}$ and $1 \% \mathrm{CaCl}_{2}$ & -0.111 & -0.061 \\
\hline $0.3 \% \mathrm{Na}_{2} \mathrm{~S}_{2} \mathrm{O}_{5}$ and $1 \% \mathrm{CaCl}_{2}$ & -0.109 & -0.063 \\
\hline
\end{tabular}

For redness and yellowness changes, the increase of both values was observed. Drying at higher temperature provided the higher change of these values. The rate of color changes seemed to be faster when above drying condition was applied. The redness values gradually increased as the enzymatic browning reaction occurred

The determination of color change during drying showed the power of image analysis process which had a capability to evaluate the change of product properties which gradually changed during drying. Therefore, this method can be used as a guideline for the on-line quality monitoring of many food processing.

Table 6. The prediction errors of the combined kinetics models for lightness values of chilli undergoing $80^{\circ} \mathrm{C}$

\begin{tabular}{|c|c|c|c|}
\hline \multirow{2}{*}{ Pre-treatment } & \multicolumn{2}{|c|}{$\boldsymbol{S} \boldsymbol{*}$} & \multirow{2}{*}{$\boldsymbol{R}^{\mathbf{2}}$} \\
\cline { 2 - 3 } & $\boldsymbol{k}_{\mathbf{0}}$ & $\boldsymbol{k}_{\mathbf{1}}$ & \\
\hline Non-treated & 0.03 & 0.04 & 0.99 \\
\hline Blanching & 0.05 & 0.06 & 0.99 \\
\hline $0.1 \% \mathrm{Na}_{2} \mathrm{~S}_{2} \mathrm{O}_{5}$ and $1 \% \mathrm{CaCl}_{2}$ & 0.03 & 0.04 & 0.98 \\
\hline $0.2 \% \mathrm{Na}_{2} \mathrm{~S}_{2} \mathrm{O}_{5}$ and $1 \% \mathrm{CaCl}_{2}$ & 0.04 & 0.05 & 0.99 \\
\hline $0.3 \% \mathrm{Na}_{2} \mathrm{~S}_{2} \mathrm{O}_{5}$ and $1 \% \mathrm{CaCl}_{2}$ & 0.02 & 0.02 & 0.98 \\
\hline
\end{tabular}

\section{Conclusions}

The fastest drying time was found at $80^{\circ} \mathrm{C}$. The rate moisture removal of pre-treated chilli was found to be decrease compared to non-treated samples (fresh) at all drying conditions due to the absorption of moisture and solutions during the blanching and soaking process. On the other hand, the chemicals pre-treatment would enhance the rate moisture removal since the $\mathrm{Na}$ and $\mathrm{Ca}$ salt components of mixed solution altered the chilli structures. However, the levels of concentration had no significant effect on the rate of moisture removal. In terms of modeling, the modified Page model was selected to describe the drying characteristics of chilli since it provided the lowest $S E(0.01-0.02)$ and highest $R^{2}(0.97-$ $0.99)$ for all drying conditions. The application of pretreatment on the chilli could improve the change of dried chilli color. The $B I$ was found to be lower when chilli had been blanched in hot water and then soaked in the mixed solution of $0.3 \%$ (w/w) $\mathrm{Na}_{2} \mathrm{~S}_{2} \mathrm{O}_{5}$ and $1 \%$ (w/w) $\mathrm{CaCl}_{2}$ prior to drying. The higher drying temperature $\left(80^{\circ} \mathrm{C}\right)$ resulted in the higher degradation of color change of dried product. Moreover, the combined kinetic model was the best fit model that could be used to predict the change of color during drying. It provided the lowest $S E$ (0.02-0.04) and highest $R^{2}(0.98-0.99)$; the estimated kinetic parameters were in the range of -0.082 to -0.137 and -0.061 to -0.078 for $\mathrm{k}_{0}$ and $\mathrm{k}_{1}$, respectively.

\section{Acknowledgement}

The authors would like to thanks Agro-Industry Research Center and Faculty of Agro-Industry, King Mongkut's University of Technology North Bangkok for the financial support through the 2015 Research Funding.

\section{References}

1. M.A. Islam, S.S. Sharma, P. Sinha, M.S. Negi, B. Neog, S.B. Tripathi, Sci. Hort., 183, 66-71(2015)

2. N. Toontom, W. Posri, S. Lertsiri, M. Meenune, Int. Food Res. J., 23, 1, 289-299 (2016)

3. W. Phomkong, S. Soponronnarit, P. Thammarutwasik, Drying Tech, 28, 12, 1466-1476 (2010)

4. R. Jinorose, R. Assawarachan, Int. Soc. Hort. Sci., 595-598 (2015)

5. H.S. Santos, M.A. Silva, Drying Tech., 26, 12, 14211437 (2008)

6. E. Uribe, D. Marín, A. Vega-Gálvez, I. QuispeFuentes, A. Rodríguez, Food Chem., 190, 559-565 (2016)

7. G.O. Sigge, C.F. Hansmann, E. Joubert, E., J. Food Qual. 22, 4, 439-452 (1999)

8. A. Hossain, L. Woods, B.K. Bala, Intl. J. Food Sci\&Tech. 42, 11, 1367-1375 (2007)

9. C. Helou, P. Jacolot, C. Niquet-Léridon, P. GadonnaWidehem, F.J. Tessier, Food Chem., 190, 904-911 (2016)

10. P. Gupta, J. Ahmed, U.S. Shivhare, G.S.V. Raghavan, G.S.V. Drying Tech., 20, 10, 1975-1987 (2002)

11. Vega-Gálvez, K. Di Scala, K. Rodríguez, R. LemusMondaca, M. Miranda, J. López, M. Perez-Won, Food Chem., 117, 4, 647-653 (2009)

12. G. Adiletta, P. Russo, W. Senadeera, M. Di Matteo, J. Food Eng., 172, 9-18 (2016)

13. J. Carranza-Concha, M. Benlloch, M.M. Camacho, N. Martínez-Navarrete, Food Bio. Proc., 90, 2, 243248(2012)

14. S.M. Oliveira, I.N. Ramos, T.R.S. Brandão, C.L.M. Silva, J. Food Process. Preserv., 39, 8, 2485-2496 (2015)

15. P. Komarnicki, R. Stopa, D. Szyjewicz, M. Młotek, Post. Bio. Tech., 114, (36-44 (2016)

16. S. Savadkoohi, H. Hoogenkamp, K. Shamsi, A. Farahnaky, Meat Sci., 97, 410-418 (2014)

17. Girolami, F. Napolitano, D. Faraone, G. Di Bello, A. Braghieri, Meat Sci, 96, 610-616 (2014)

18. P.M. Szczypiński, A. Klepaczko, P. Zapotoczny, Comp. Elec. Agri., 110, 1-8 (2015)

19. AOAC, Official methods of analysis of AOAC International, 17, (2000)

20. S.D.F. Mihindukulasuriya, H.P.W. Jayasuriya, Agri. Eng. Int.: CIGR Journal, 15, 154-166 (2013) 
21. M.L.B. Ávila, C.L.M. Silva, J. Food Eng., 39, 2, 161-166 (1999)

22. C.R. Chen, H.S. Ramaswamy, LWT - Food Sci \&Tech., 35, 5, 415-419 (2002)

23. M. Maskan, J. Food Eng., 48, 2, 169-175 (2001)

24. G. Dadali, E. Demirhan, B. Özbek, Drying Tech., 25, 10, 1703-171 2 (2007)

25. R. Saengrayap, A. Tansakul, G.S. Mittal, J Food Sci\&Tech., 52, 5, 2610-2621 (2015)
26. N.C. Acevedo, C. Schebor, P. Buera, Food Chem., 108, 3, 900-906 (2008)

27. L. Manzocco, S. Calligaris, D. Mastrocola, M.C. Nicoli, C.R. Lerici, Trends in Food Sci\& Tech., 11, 9-10, 340-346 (2000)

28. S. Azeez, O. Lasekan, S. Jinap, R. Sulaiman, J. Food Sci.\&Tech., 52, 8050-8058 (2015)

29. G. Sacchetti, F. Ioannone, M. De Gregorio, C. Di Mattia, M. Serafini, D. Mastrocola, J. Food Eng., 169, 44-52 (2016) 